\title{
Coronary sinus and subvalvular left ventricular
}

\section{aneurysm}

\author{
Apsley Pellatt \\ From the Department of Anatomy, Faculty of Medicine, University of Rhodesia, Salisbury, \\ Rhodesia
}

The anatomy of the coronary sinus is briefly reviewed. Atrial reflux and efficiency of the ostial valve are examined. $A$ heart showing a posterobasal left ventricular aneurysm is described, and it is suggested that concomitant obstruction of the sinal ostium may have caused the aneurysm. $A$ simple flow experiment, and examination of 100 routine postmortem hearts and 42 foetal hearts suggest that: (i) atrio-sinal reflux does not normally occur except in foetal life; (ii) the valve of the coronary sinus ostium is probably a vestigial structure with little efficiency; and (iii) some cases of submitral aneurysm may be due to obstruction of the coronary sinus.

The coronary sinus is the terminal channel of the coronary venous system. It drains the bulk of the blood from the vascular bed of the left coronary and a small part of that of the right coronary artery (Gregg, 1948). It is 2-3 $\mathrm{cm}$ long, $0.5-1.0 \mathrm{~cm}$ in diameter, lies on the back of the heart in the posterior atrioventricular groove, and opens into the right atrium between the orifices of the inferior vena cava and the tricuspid valve (Davies, 1967).

The ostium of the coronary sinus is described as being guarded by a semilunar endocardial valve (Thebesian valve) which covers the lower part of the orifice. It is said to prevent regurgitation of blood into the sinus during atrial systole, and may be double or cribriform (Davies, 1967).

$A$ priori certain questions arise.

Is there any tendency for significant atriosinal reflux during atrial systole in the normal heart ? Contraction of the atrium causes only minor reflux into the superior vena cava (a large channel with a valveless ostium) contributing to the ' $a$ ' wave of the jugular venogram, and the right ventricle relaxing in diastole (during atrial systole) easily sucks in blood through the wide tricuspid orifice. It seems improbable that any important degree of sinal reflux even tends to occur.

Koberstein, Pittman, and Klocke (1969), using a sophisticated blood $\mathrm{H}_{2}$ dilution technique, have clearly shown in dogs that reflux of right atrial blood into the coronary sinus

Received 2 August 197 I. occurs to the extent of causing a 5-6 per cent admixture $1-2 \mathrm{~cm}$ proximal to the ostium only when right ventricular pressure is artificially raised by partial occlusion of the pulmonary artery. With normal haemodynamics no sinal reflux occurs.

Also working with dogs, Stein et al. (1969), in experiments with an electromagnetic flowtransducer attached to the tip of a cardiac catheter positioned in the coronary sinus $\mathrm{I}-4$ $\mathrm{cm}$ from the ostium, have shown that reversal of blood flow, if indeed it occurs at all, constitutes less than I per cent of forward flow.

Would these findings be valid for the human heart? Assuming however that appreciable reflux does in fact tend to take place, how efficient an antireflux valve is a single semilunar cusp (covering about $50 \%$ of the ostium as usually depicted) likely to be ? The question is posed for postnatal conditions: during embryonic or foetal life circumstances may well be different.

If the greater part of the coronary blood from the left heart is drained into the coronary sinus, would obstruction of the sinus or its ostium predispose to myocardial damage in the region of impeded drainage? The theoretical possibility exists that infarction secondary to venous occlusion might occur. Gregg (1948) in his review of the coronary circulation quotes evidence that in dogs acute experimental closure of the coronary sinus alone causes no great reduction in coronary arterial (and therefore coronary capillary) flow. In dogs where both coronary sinus and anterior cardiac veins (the latter draining most of the right 
coronary blood directly into the right atrium) have been occluded in a two-stage operation, the animals have survived for a period of months, due to development of several large extramyocardial venous anastomoses and numerous superficial cardiac veins of considerable size which were not previously evident.

Whether these findings in dogs are applicable to the human heart is unknown at present. Bearing in mind the high incidence of coronary arterial insufficiency in human hearts, a degree of coronary venous occlusion might well be highly significant.

Valid answers to all these questions concerning the coronary sinus in man will only be made when experimental evidence concerning sinal flow and pressure changes under varying conditions is available.

\section{Case report}

These questions recently acquired added relevance when a heart with a left ventricular aneurysm was sent to the Department of Anatomy by Dr. T. Ashworth of the Department of Pathology. The heart was that of an adult male African, estimated age 60 years (PM 30r/70, Harari Hospital). Relevant clinical findings are as follows: the deceased was admitted to hospital on 23 June 1970, for decompression of thoracic spinal tuberculosis. He died for no apparent reason on 3 August 1970. No previous history is available. Apart from the heart condition, necropsy revealed active chronic pyelonephritis without hypertensive changes, and spinal tuberculosis.

The aneurysm was situated on the posterior wall of the ventricle behind the posterior cusp of the mitral valve (Fig. I). The aneurysmal wall was composed of hard fibrous tissue, only 2-3 $\mathrm{mm}$ thick at its deepest part. A central zone of calcification which gave a metallic tinkle when tapped with an instrument was later confirmed radiographically. The aneurysm measured $4 \mathrm{~cm}$ at its mouth, was $3 \mathrm{~cm}$ deep, and raised a smooth, fairly well-defined bulge over the posterolateral aspect of the external surface of the ventricle (Fig. 2). Over and around this bulge was a well-marked fibrous pericarditis (Fig. 2a). No other abnormalities were noted, and in particular the coronary arteries were normal. A retrograde coronary venogram shows the relation of the aneurysm to the coronary sinus (Fig. 3).

A diagnosis of submitral left ventricular aneurysm of unknown aetiology was made. In view of reports of similar lesions from other parts of Africa, and especially in view of tentative suggestions by other workers that the aetiology may be a developmental anomaly of the 'fibrous valve ring' (Edington and Gilles, 1969; Abrahams et al., 1962), this heart was referred to the Department of Anatomy for further investigation.

Preliminary examination confirmed the necropsy findings. The fibrous valve ring was intact and apparently normal. The coronary arteries were examined under a magnifier $(2 x)$ and appeared normal. In particular, no atheroma, thrombosis, or narrowing could be demonstrated in the circumflex branch of the left coronary artery supplying the region of the aneurysm.

The epicardial surface of the whole left ventricle showed obvious 'venularity', i.e. a network of numerous, dilated, and slightly tortuous venules highly reminiscent of the skin of the lower limb in the presence of severe saphenous vein insufficiency. In addition the posterior vein of the left ventricle was very dilated, and the middle cardiac vein somewhat less so. There was no narrowing or other abnormality of the channel of the coronary sinus itself.

The ostium of the coronary sinus, however, appeared grossly abnormal. It was almost completely occluded by an endocardial septum in which were two small perforations each $\mathrm{r}$ to $2 \mathrm{~mm}$ in diameter (Fig. 4). The surface of this septum was smooth and neither it nor the margin of the ostium showed any sign of vegetations, petechiae, thickening, or other pathological features. The edges of the perforations were well defined.

No other abnormalities could be seen in this heart.

It seemed obvious that normal coronary sinus flow could not possibly have taken place through these two minute apertures. It was, therefore, postulated that the aneurysm was secondary to chronic myocardial ischaemia caused by venous insufficiency in just that region of the left ventricle most likely to suffer the effects of chronic obstruction of flow in the coronary sinus due to a congenital ostial septum.

Other postulated contributory factors were: (I) the postmitral region is normally the thinnest part of the left ventricular wall; and (ii) at maximal systolic contraction this region of the ventricular cavity behind the posterior mitral cusp (itself bulged into the atrium during systole) must be a 'pressure cul de sac' in which maximal left ventricular pressure is developed.

Search of the published material revealed reports of 40 to 50 cases of subvalvular (submitral and/or subaortic) left ventricular aneurysm, almost all in Negro subjects. In all but a very few of these no aetiology had been determined. Without exception the often detailed necropsies make no mention of the coronary veins. In particular the state of the coronary sinus and its ostial valve are never once referred to in these reports (Brink and Barnard, 1954; Chesler et al., 1965; Edington and Williams, 1968; Higginson and Keely, 195I; Lurie, 1960; Pocock et al., 1965; Robertson and Jackson, 1960).

Therefore, it was felt that the findings in this heart merited further study, as there seemed to be a reasonable 'prima facie' case that the aetiological connexion postulated above might be correct. Three lines of inquiry were accordingly pursued.

\section{Methods}

In an attempt to establish that sinal flow must have been reduced, a simple flow experiment was 

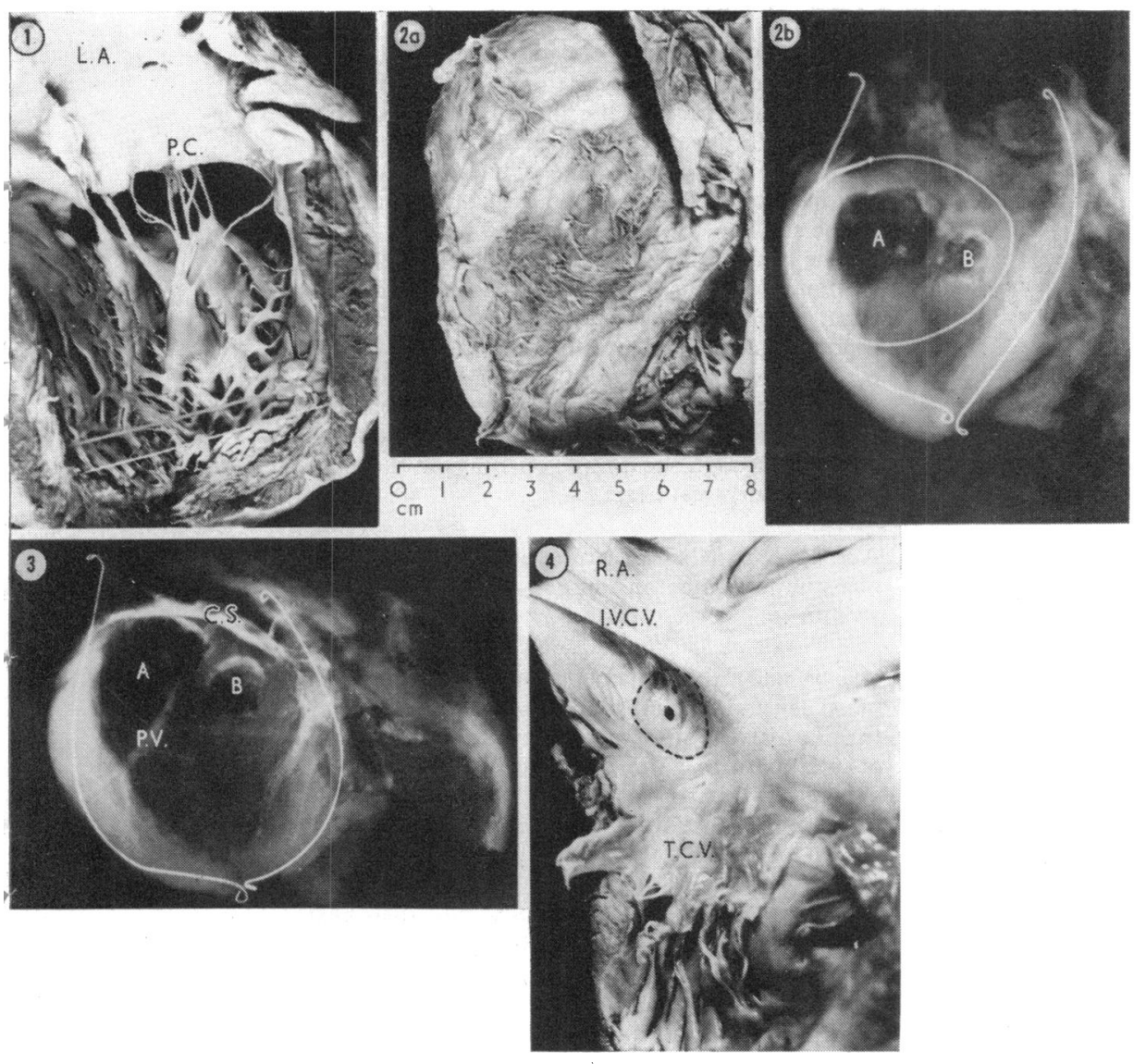

FIG. I Interior of left chambers of heart (PM 301/70, Harari Hospital), showing mouth of large submitral aneurysm. LA, left atrium; PC, posterior cusp of mitral valve.

FIG. 2a Posterior surface of left ventricle showing well-marked fibrous pericarditis.

FIG. 2b X-ray of heart (PM 301/70). Vertical wires mark position of cut edges of opened

left ventricle. Circular wire marks limit of the aneurysmal bulge on external surface of ventricle. Note two partly separated loculi of the aneurysm $(A$ and $B)$, and calcification especially in the smaller loculus. Posterior view. FIG. 3 X-ray of same heart showing position of aneurysmal loculi relative to coronary sinus (CS). PV, posterior vein of left ventricle. $A$ and $B$ as in Fig. 2. Posterior view. FIG. 4 Ostium of coronary sinus (margin dotted) of heart (PM 301/70) showing its occlusion by an endocardial septum perforated by two minute apertures. TCV, 'tricuspid valve; $R V$, right ventricle; $R A$, right atrium; IVCV, valve of inferior vena cava. (These abbreviations also apply to Fig. 5-II).

performed to compare flow rate in this heart with that in a normal heart having a patent sinal ostium Io $\mathrm{mm}$ in diameter.

A reservoir of water was mounted on a stand above the heart. From this a tube was led and tied into an opening made into the coronary sinus 2.5 $\mathrm{cm}$ from the ostium. The apparatus was connected with a mercury manometer and the height of the reservoir adjusted to give a pressure of $80 \mathrm{mmHg}$. Flow through the ostium into the right atrium was observed and collected over a period of I minute. The procedure was repeated three times with each heart, and flow through tube alone was also measured three times. The results are as follows, each figure being the mean of three closely similar readings.

Normal heart: minute flow through tube alone, $450 \mathrm{ml}$; minute flow through tube and coronary sinus, $450 \mathrm{ml}$.

Pathological heart: minute flow through tube and obstructed coronary sinus, $375 \mathrm{ml}$.

This reduction in flow of 17 per cent was smaller than expected, but the experimental conditions 
TABLE I Variations in structure of the valve of the coronary sinus in 100 unselected African cadavers

\begin{tabular}{|c|c|c|}
\hline & Male & Female \\
\hline $\begin{array}{l}\text { No valve } \\
\text { Single string: } \\
\text { Thin }<\mathrm{I} \cdot 0 \mathrm{~mm} \cdot \\
\text { Thick }>\mathrm{I} \cdot 0 \mathrm{~mm} \\
\text { Multiple strings } \\
\text { Band or valve with numerous } \\
\text { fenestrations } \\
\text { Band or valve with one or two } \\
\text { renestrations }\end{array}$ & $\left.\begin{array}{l}2 \\
2 \\
2 \\
1\end{array}\right\}$ & $\left.\begin{array}{l}2 \\
1 \\
2 \\
1 \\
2\end{array}\right\}$ \\
\hline $\begin{array}{l}\text { Full valve } \\
\text { Covering less than } 1 \text { of ostium } \\
\text { " } \frac{1-\frac{1}{2} \text { of ostium }}{\text { " } \frac{1}{2}-\frac{3}{4} \text { " }} \\
\text { " } \frac{3}{4} \text { or more of ostium }\end{array}$ & $\begin{array}{r}2 \\
15 \\
36 \\
3\end{array}$ & $\begin{array}{r}2 \\
10 \\
14 \\
1\end{array}$ \\
\hline Total: 100 & 63 & 37 \\
\hline
\end{tabular}

were so artificial (water instead of blood, immobile formalized heart, empty right atrium, continuous as opposed to pulsatile flow, etc.) that the precise degree of flow reduction is probably meaningless. The experiment merely serves to confirm that blood flow through the abnormal ostium must have been significantly reduced.

\section{Material}

A) One hundred hearts were examined at necropsy to determine the normal range of variation of the coronary sinus and its ostium. The cases were wholly unselected and included both police and hospital material.

Each heart was examined externally, particular note being made of the disposition of the sinal tributaries. Thereafter all heart chambers were opened and a detailed inspection made. Particular attention was paid to the coronary arteries and to the anatomy of the coronary sinus ostium. The findings are presented in Table $\mathrm{I}$.

Fig. 5-I I show the variations listed in Table I.

The preponderance of males $(63 \%)$ is explained partly by the normally higher proportion of male in-patients at Harari Hospital, and partly by the still higher proportion of males in the total number of medicolegal necropsies $(60 \%$ and $76 \%$, respectively).

It should be noted that the textbook description of the 'normal' valve is what in Table $I$ is termed a 'full valve', i.e. a single semilunar cusp based on the posteroinferior margin of the ostium, without superfluous strings, and covering approximately half of the aperture. Table I shows that 7 (I $\%$ ) male subjects and ro (27\%) female subjects have abnormal valves. In no case is there any narrowing of the ostium, whatever the state of development of the valve. Even in those subjects with cusps covering more than three-quarters of the ostium in the closed position, there is ample room for sinal blood flow into the atrium. The maximum degree of valve coverage, in the closed position, seen was 100 per cent, which occurred in only one case. No specimen showed a condition remotely approaching the almost complete occlusion seen in the abnormal heart.

Table 2 shows the range of measurements of the diameter of the ostium in the 52 adult subjects in the series.

The bulk of these measurements clusters round Io $\mathrm{mm}$. No adults have very small ostia $(5 \mathrm{~mm}$ or less): 4 per cent have very large ostia ( $16 \mathrm{~mm}$ or more). The smallest measurement in an adult was $6 \mathrm{~mm}$, and in this case calculation of the crosssectional area shows a channel permitting much more copious blood flow than could have been possible through the minute openings in the valve of the aneurysmal heart.

Normal heart: diameter of ostium, $6 \mathrm{~mm}$; radius of ostium, $3 \mathrm{~mm}$; and cross-sectional area $\left(\pi^{2}\right)$, $28 \mathrm{~mm}^{2}$.

Aneurysmal heart: diameter of each aperture in ostial septum, $2 \mathrm{~mm}$ (max.); radius of each aperture in ostial septum, I mm; cross-sectional area of each aperture, $3 \mathrm{~mm}^{2}$; combined cross-sectional area of both apertures, $6 \mathrm{~mm}^{2}$; and therefore ratio of cross-sectional areas is $28 / 6$ or approximately 5 .

Thus flow through the abnormal ostium is likely to have been appreciably less than that through the smallest adult ostium seen in the series of 100 cases.

B) A series of 42 foetal hearts in the Department of Anatomy has also been examined to determine their ostial morphology. The foetuses included African and European specimens, and in fertilization age they ranged from $13-26$ weeks (CR length $7.5-22.0 \mathrm{~cm}$ ). During this age period the diameter of the sinal ostium is $\mathrm{I}-2 \mathrm{~mm}$. The findings are shown in Table 3.

These findings indicate the following.

i) In 5 cases ( $12 \%$ ) the valve completely covers the ostium (roo\% coverage) when in the closed position. This contrasts with the postnatal series (Table I) where maximal coverage was of the order of 70-75 per cent in 3 cases and roo per cent in only one.

ii) In no case was the valve completely absent: this contrasts with total absence in two females in Table I.

iii) In only one case was an 'abnormal' valve seen, showing a single large fenestration in an otherwise normal cusp. Even here ostial coverage was 30 per cent. No case of multiple fenestration or reduction to single or multiple strings was seen.

iv) No case of almost total occlusion comparable with that in the aneurysmal heart was seen.

The tentative conclusion may be drawn that during foetal life the valve of the coronary sinus tends to be better developed than in postnatal life. During foetal life reflux into the coronary sinus may be potentially greater due to the copious 

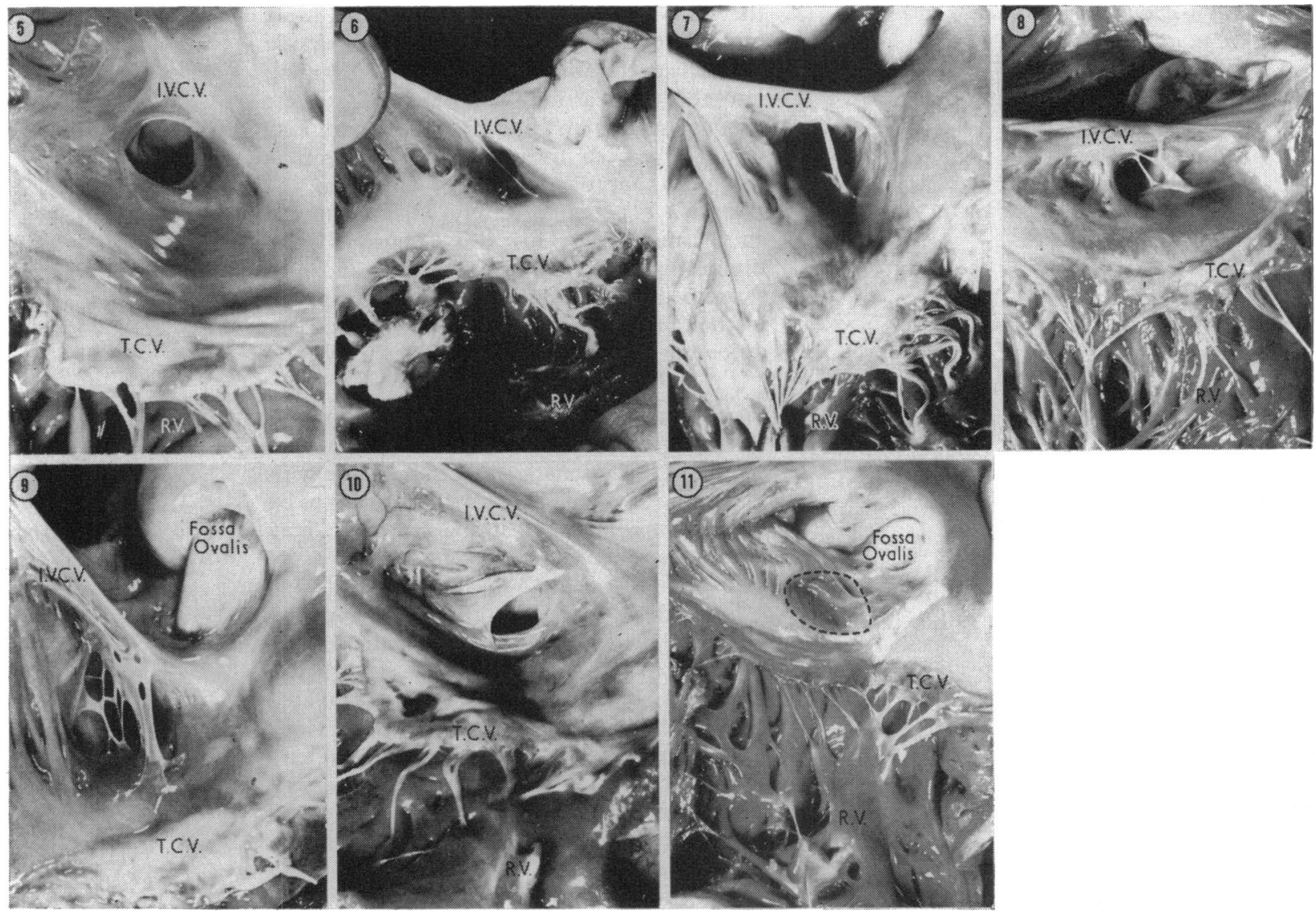

FIG. 5 Ostium of coronary sinus. Specimen showing complete absence of valve (see Table I). FIG. 6 Ostium of coronary sinus spanned by single thin endocardial string. FIG. 7 Ostium spanned by a single thick endocardial string. FIG. 8 Ostium spanned by multiple strings. FIG. 9 Ostium covered by valve with numerous fenestrations. FIG. IO Ostium covered by 'full valve' giving 50 per cent cover. FIG. II Ostium covered by 'full valve' giving 100 per cent cover. This was the only example in roo postnatal cases. The next highest degree of cover $(75 \%)$ was only seen in 3 cases. (Ostial margin dotted.)

stream of blood (mainly of placental origin) which passes across the right atrium from inferior vena cava to foramen ovale immediately above the ostium of the coronary sinus. Sudden increase of flow due to maternal muscular activity would tend to raise foetal right atrial pressure, further aggravating the tendency to sinal reflux. In these circumstances a more efficient valve would be advantageous.

\section{Discussion}

(i) Examination of the morphology of the ostium of the coronary sinus in 100 postnatal cadavers and in $\mathbf{4 2}$ foetuses in the midgestational trimester makes it clear that there is great variation in development of the sinal valve, ranging from full ostial coverage in the closed position in foetal life to complete absence in postnatal life.

Complete absence of the valve, obvious fenestration to form a flimsy net, or its reduction to one or more endocardial strings in not a few cases - conditions which preclude any valvular action, without apparent functional disturbance - force the conclusion that in postnatal life this valve is a vestigial structure of minimal importance.

Its more complete development during foetal life may be of functional significance in preventing excessive sinal reflux during periods of augmented placental return.

The suggestion is made that after the normal postnatal circulatory changes have taken place, further growth of the valve in all cases 
TABLE 2 Diameter of ostium of coronary sinus in 52 adult subjects

\begin{tabular}{lrl}
\hline Diameter of ostium & Male & Female \\
\hline $5 \mathrm{~mm}$ or less & - & - \\
$6-10 \mathrm{~mm}$ & 23 & 9 \\
1 $1-15 \mathrm{~mm}$ & 15 & 3 \\
$16 \mathrm{~mm}$ or more & 2 & - \\
\hline Total adults: 52 & 40 & 12
\end{tabular}

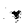

lags behind enlargement of the ostium, with the result that valvular closure is almost always much less than 100 per cent, whereas in foetal life total closure is more common. Furthermore, it is suggested that in keeping with the altered right atrial haemodynamics of postnatal life, the ostial valve is less subjected to functional stress and as a result often undergoes a process of degeneration and reduction, in a few cases to the point of disappearance.

(ii) Simple experiment showed that flow through a normally patent ostium of average diameter (IO $\mathrm{mm}$ ) is likely to be significantly greater $(17 \%)$ than flow through an ostium occluded by a septum having only two small apertures of $I$ to $2 \mathrm{~mm}$ each, such as was present in the aneurysmal heart. Calculation of the cross-sectional area of the smallest adult ostium seen (diameter $6 \mathrm{~mm}$ ) shows it to be five times greater than the combined area of the two apertures in the occluding septum. The ratio of blood flow is likely to be of a similar order of magnitude.

This seems to indicate that flow through these apertures must have been grossly inadequate, and that much of the blood from the left coronary bed of the aneurysmal heart must have been shunted through anastomotic channels to the anterior cardiac veins draining into the right atrium. The area of greatest venous stagnation under these conditions would have been in the channel of the coronary sinus approximately $2-3 \mathrm{~cm}$ from the ostium - a region precisely adjacent to the aneurysmal area. This area is normally the thinnest part of the left ventricle, and also sustains the high pressure of blood 'trapped' in the 'pressure cul-de-sac' behind the posterior mitral cusp during ventricular systole.

(iii) No case in either the postnatal or the foetal series showed any occlusion of the ostium of the coronary sinus comparable with that in the aneurysmal heart. This seems to be supportive evidence that the aneurysm may indeed have developed secondarily to ostial occlusion.

Since these investigations were completed however, two other hearts from the Harari Hospital mortuary showing left ventricular submitral aneurysms have become available for examination. In one the cause was obvious - a total atherosclerotic occlusion of the circumflex branch of the left coronary artery immediately adjacent to the aneurysm (Fig. 12 and 13). In both of these hearts the coronary sinus and its ostium were normal. These findings make it clear that the aetiology of submitral left ventricular aneurysms may involve several factors.

(iv) Bland, White, and Garland (1933) reported the occurrence, in an infant dying at the age of 3 months, of an abnormal origin of the left coronary artery from the pulmonary artery, associated with marked dilatation of

TABLE 3 Variation in structure of valve of coronary sinus in 42 foetuses in mid-trimester of gestation

\begin{tabular}{|c|c|c|c|c|c|c|c|}
\hline \multirow{2}{*}{ Foetal age } & Male & & & Female & & & \\
\hline & $\begin{array}{l}16-18 \\
w k\end{array}$ & $\begin{array}{l}I 9-2 I \\
w k\end{array}$ & $\begin{array}{l}25-26 \\
w k\end{array}$ & $\begin{array}{l}13-15 \\
w k\end{array}$ & $\begin{array}{l}19-2 I \\
w k\end{array}$ & $\begin{array}{l}22-24 \\
w k\end{array}$ & $\begin{array}{l}25-26 \\
w k\end{array}$ \\
\hline
\end{tabular}

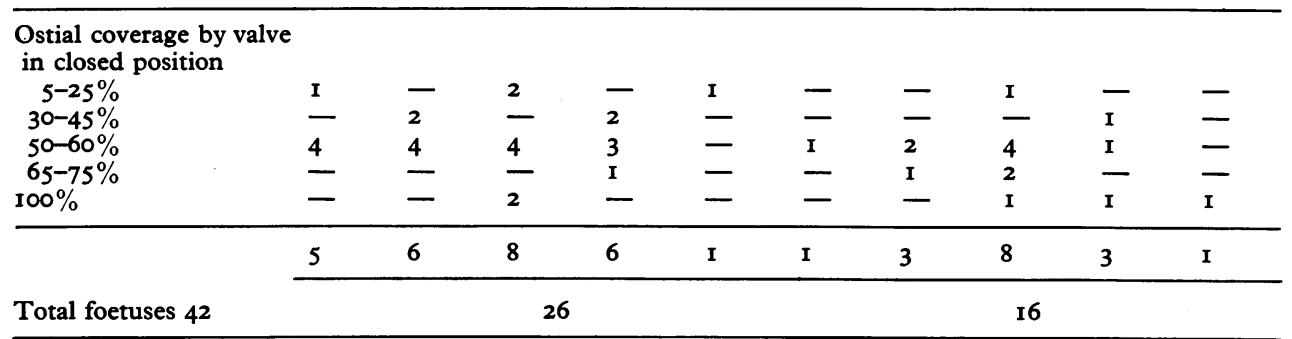


the left ventricle, severe fibrosis of the endocardium, and occasional fibrotic patches at deeper levels. Concomitant apparent hypertrophy of the ventricular wall 'was due in part to an increase in the number of muscle fibres, and in part to separation of muscle bundles by unusually large spaces, the result of vascular dilatation together with a small amount of fibrosis between the bundles'. The size of individual muscle fibres was not appreciably greater than normal.

Their illustration of the interior of the left ventricle in their case shows a notably similar appearance to that of the aneurysmal region in the present case - obvious fibrotic trabeculae thrown into high relief by the rounded 'blown-out' spaces between them.

The authors make the significant comment that the, 'parenchymal changes are dependent in large part upon two factors: (I) the inadequate nourishment of the ventricular wall by venous blood and (2) the relatively low pressure in the coronary artery arising from the pulmonary artery'. They further note, 'the striking similarity of the ... degenerative changes ... to those arising ... secondary to coronary artery sclerosis'.

Venous blood moving sluggishly at low pressure by hypopulsatile flow would likewise result from occlusion of the coronary sinus, with presumably similar consequences for myocardial fibres in the vulnerable subvalvular region of the left ventricle. Due to multiple coronary venous anastomoses, these sequelae would of course take far longer than three months to develop. Most of the reported cases of subvalvular aneurysms have only become clinically apparent in the second or third decades of life.

(v) Hudson (1970) has reviewed the anomalies of the coronary sinus. Four main groups are distinguished. (a) Enlargement. (b) Absence. (c) Hypoplasia. (d) Atresia of the ostium.

Both text and illustrations show that in virtually every case these anomalies are accompanied by other gross, often multiple, cardiac abnormalities. Furthermore, blood prevented from flowing through a narrowed or absent coronary sinus is drained by one of the following channels. (i) A persistent left superior vena cava. (ii) A pulmonary vein, usually the left inferior. (iii) Enlarged Thebesian veins draining directly into the atria.

Left ventricular aneurysm is conspicuously absent in these cases of obstructed coronary sinus flow. This is only to be expected, since, in effect, flow is not obstructed but merely diverted into the foregoing channels.
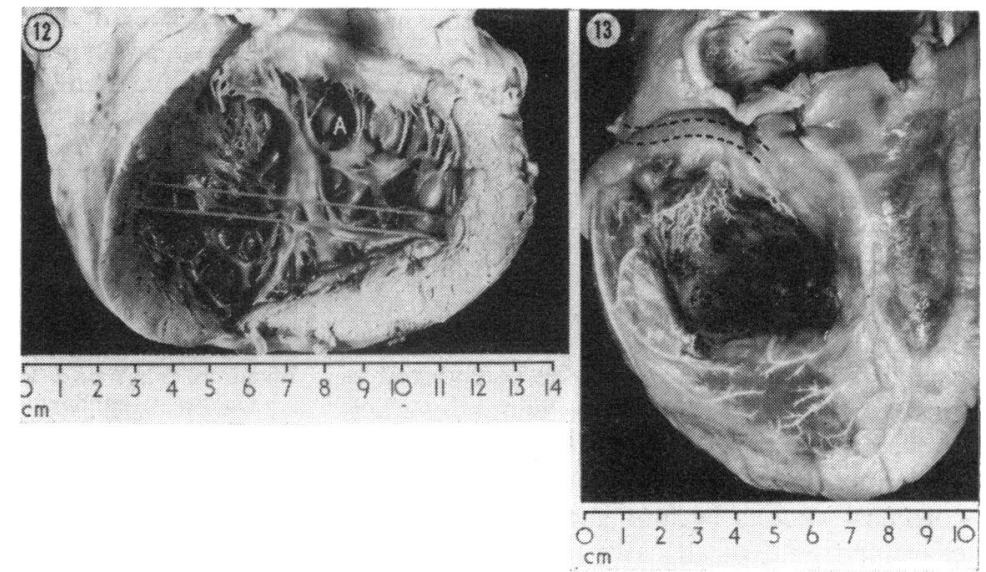

FIG. I2 Interior of left ventricle (PM

8II/70, Harari Hospital) showing mouth of

submitral aneurysm $(A)$.

FIG. I3 Posterior surface of left ventricle

(PM 8II/70) showing haemorrhagic aneurys-

mal bulge on external surface. Position of

atherosclerotic section of circumflex branch of

left coronary artery dotted. Veins outlined by

radio-opaque material.

Hudson states that atresia of the ostium 'may occur in isolation or with other anomalies; 3 types were seen': he then describes the three types occurring with other anomalies. No further mention is made of isolated atretic ostia; the number of examples described is not stated, and the condition is not illustrated.

Yet it is precisely this isolated ostial atresia, with no easy alternative drainage channels, which could conceivably result in chronic, localized, left ventriculat myocardial venous congestion and consequent mural weakening.

Hudson also reviews the published reports on cardiac aneurysm in the African and quotes that of Chesler et al. (1965), 'The aneurysms seemed to be due to a congenital weakness of the left ventricular wall near the atrioventricular junction, permitting endocardial herniation.' As already noted earlier in this paper, Edington and Gilles (1969) and Abrahams et al. (1962) have also expressed this opinion.

Some of these aneurysms may well be congenital, in the sense that the herniation may have begun in early life, or in that the predisposing cause may have been insidiously operative from an early stage. What is this predisposing cause? May it not be, in some cases at least, inadequate perfusion of the affected region of myocardium ? After all, the 
oné s̄oundly established causal mechanism fòr certain examples of left ventricular aneurysm is coronary arterial occlusion resulting in poor myocardial perfusion. Localized venous insufficiency would likewise result in reduced tissue perfusion, albeit at a slower tempo.

Isolated atresia of the ostium of the coronary sinus without alternative large drainage channels (dilated Thebesian veins, persistent left superior vena cava, or other extramyocardial anastomoses) should be considered as a possible cause of localized venous insufficiency. In all future cases of otherwise unexplained left ventricular aneurysm the coronary venous system should be critically examined, and in all cases of isolated atresia of the sinal ostium the left ventricular myocardium in the region of the atrioventricular junction should be investigated for signs of venous congestion and tissue degeneration.

(vi) The questions posed early in the paper may now be accorded tentative answers.

(a) Significant atrio-sinal reflux probably does not tend to occur in postnatal life, but may well be of importance in foetal life.

(b) Efficiency of the ostial valve of the coronary sinus probably parallels the tendency to atrio-sinal reflux. Manifestly a valvular cusp covering only half or even less of the ostium is not very efficient. Absence or reduction of the cusp to a net or even a single endocardial string indicates that little efficiency is required, at any rate during postnatal life.

(c) In at least some cases of submitral aneurysm, impeded drainage through the coronary sinus may result in venous congestion and myocardial damage. Congenital maldevelopment of the valve of the ostium of the coronary sinus resulting in the formation of an occluding septum appears to be one possible cause of such impeded drainage.

Sincere thanks are due to the following persons who have contributed to this study: Dr. T. Ashworth and Dr. N. Gane of the Department of Pathology, and Dr. M. Ross and Dr. K. Lee of the Government Pathology Laboratory at Harari Hospital, all of whom collected postmortem material for examination. Mr. N. Lyons and Mrs.
G. Herrington of the Department of Pathology for the excellent photographs; Miss G. Warren for assistance in examination of specimens; and the Secretary for Health for access to material at the Harari Hospital Mortuary.

\section{References}

Abrahams, D. G., Barton, C. J., Cockshott, W. P., Edington, G. M., and Weaver, E. J. M. (1962). Annular subvalvular left ventricular aneurysms. Quarterly fournal of Medicine (n.s.), 3I, 345.

Bland, E. F., White, P. D., and Garland, J. (1933). Congenital anomalies of the coronary arteries: report of an unusual case associated with cardiac hypertrophy. American Heart fournal, 8, 787.

Brink, A. J., and Barnard, P. J. (1954). Syphilitic aneurysm of the left ventricle of the heart with calcification and ossification. South African Medical, Fournal, 28, 476.

Chesler, E., Joffe, N., Schamroth, L., and Meyers, A. (1965). Annular subvalvular left ventricular aneurysms in the South African Bantu. Circulation, 32, 43.

Davies, D. V. (1967). Gray's Anatomy, 34th ed. Longmans, Green, London.

Edington, G. M., and Gilles, H. M. (1969). Pathology in the Tropics, p. 317. Edward Arnold, London.

Edington, G. M., and Williams, A. O. (I968). Left atrial aneurysms associated with annular subvalvular left ventricular aneurysms. Fournal of Pathology and Bacteriology, 96, 273.

Gregg, D. E. (1948). The coronary circulation. Physiological Reviews, 26, 28.

Higginson, J., and Keely, K. J. (195I). An unusual cardiac aneurysm in a young adult. Fournal of Clinical Pathology, 4, 342.

Hudson, R. E. B. (1970). Cardiovascular Pathology, Vol. III, pp. S.400 and S.998. Edward Arnold, London.

Koberstein, R. C., Pittman, D. E., and Klocke, F. J. (1969). Right atrial admixture in coronary venous blood. American fournal of Physiology, 216, 531 .

Lurie, A. O. (1960). Left ventricular aneurysm in the African. British Heart fournal, 22, 18r.

Pocock, W. A., Cockshott, W. P., Ball, P. J. A., and Steiner, R. E. (1965). Left ventricular aneurysms of uncertain aetiology. British Heart fournal, 27, I84.

Robertson, J. H., and Jackson, J. G. (1960). Cardiac aneurysms in Nigeria. Fournal of Pathology and Bacteriology, 80, ror.

Stein, P. D., Badeer, H. S., Schvette, W. H., and Glaser, J. F. (1969). Pulsatile aspects of coronary sinus blood flow in closed-chest dogs. American Heart fournal, 78, 331.

Requests for reprints to Dr. Apsley Pellatt, Department of Anatomy, Faculty of Medicine, University of Rhodesia, Private Bag M.P. I67, Mount Pleasant, Salisbury, Rhodesia. 